\title{
MURILO MENDES: MEMÓRIA E VIDA CULTURAL
}

\author{
Lis Yana de Lima Martinez ${ }^{87}$ \\ Lúcia Sá Rebello ${ }^{88}$
}

RESUMO: Resultado de pesquisa que buscou compreender o humor, o lirismo, a memória e a história, contidos nas cartas de Murilo Mendes a Guilhermino César, como elemento fundamental para o processo de construção da identidade coletiva, este artigo procura ressaltar que a epistolografia é, sobretudo no caso da história literária brasileira, essencial para a reconstituição da memória e da história de um indivíduo e seu contexto sociocultural. Em suas epistolas, além de informações sobre sua vida cotidiana, observações a respeito de integrantes de seu ciclo de amizades, Murilo insere poemas de sua criação, comentários críticos sobre a literatura brasileira na época e movimentações sociais e literárias que ocorriam no país.

PALAVRAS-CHAVE: Literatura Comparada, mediação de espaços, Literatura Epistolar, Murilo Mendes.

ABSTRACT: This article is a result of a project that sought to understand humour, lyricism, memory and history contained in the letters of Murilo Mendes to Guilhermino César as a fundamental element for the process of construction of the collective identity. Its main objective is to emphasize that epistolography is, especially in the case of the Brazilian literary history, essential to reconstruct the memory and the history of an individual and its sociocultural context. In his epistles, in addition to information about his daily life and comments about members of his cycle of friends, Murilo inserts poems of his creation, critical comments on Brazilian literature at the time and the social and literary movements that occurred in the country.

KEYWORDS: Comparative Literature, spaces intermediation, Epistolary Literature, Murilo Mendes.

${ }^{87}$ Doutoranda do Programa de Pós-Graduação em Letras do Instittuto de Letras da UFRGS.

${ }^{88}$ Professor Titular do Departamento de Letras Clássicas e Vernáculas do Instituto de Letras da UFRGS. 


\section{PALAVRAS INICIAIS}

Talvez Murilo Mendes seja o poeta mais radicalmente poeta da literatura brasileira, na medida em que nunca escreveu senão poesia, mesmo quando escrevia sob a aparência de prosa. Candido, Poesia e ficção na autobiografia, 1989.

Este artigo, referente ao epistolario de Murilo Mendes, e proveniente da última etapa do projeto de pesquisa Estudo da Correspondencia de Murilo Mendes com Guilhermino Cesar. Literatura Comparada e História Cultural: A Mediação de Espaços Textuais que, vinculado à linha de Teorias Literárias e Interdisciplinaridade, do programa de Pós-Graduação em Letras da Universidade Federal do Rio Grande do Sul.

Este projeto, iniciado em 2008, se propunha a analisar a mediação de espaços textuais na correspondência mantida entre Murilo Mendes e Guilhermino Cesar no século XX, com o objetivo de se entender como se constrói a relação entre o universo literário e os elementos culturais e pessoais e veio para complementar um estudo de literatura epistolar, já iniciado com Horácio, dando continuidade ao trabalho iniciado pela Prof. Tania Franco Carvalhal. A fundamentação teórico-metodológica foi evidenciada em um exame preliminar das cartas de Murilo Mendes para Guilhermino Cesar, ressaltando o seu significado no contexto literário brasileiro, com dados que se inserem na história cultural do país, além de contribuirem para a ampliação do conhecimento - que até aqui se tem da obra de cada um dos autores. Deste modo, o comparatismo interrelaciona vários elementos e reafirma sua condição de procedimento interdisciplinar e permeador de espaços.

As cartas e os poemas são capazes de mediar passado e presente, pois estabelecem nexo entre espaços, aproximam quem está aqui e agora do que, distante, se perde no tempo. A função pragmática das cartas - a que motiva e justifica sua escrita - quer dizer, a necessidade dos contatos, de enviar mensagens, de contar e de informar se associa, no universo da poesia, a outras finalidades menos práticas e objetivas, mas seguramente igualmente necessárias como a de alimentar o imaginário e a de resgatar o perdido. 
À natureza da pesquisa compareceram as relações essenciais entre literatura comparada e história cultural sobre a articulação entre os espaços textuais e o papel da correspondência entre escritores nesses contextos. Nesse sentindo, ressalta-se ainda a natureza retórica da reflexão que quis dar conta de aspectos importantes à instalação e ao funcionamento dos cenários nos quais se movimentam os textos. Igualmente, a pesquisa possuiu o caráter de elucidar sobre a vida literária brasileira, uma vez que tratou de examinar documentação inédita de escritores notáveis de nossa literatura.

O tratamento do espaço íntimo manifesto nas cartas e do espaço coletivo que elas também expressam permitiram o surgimento de questões teórico-metodológicas da atualidade, em se tratando da relação entre vida pessoal, história literária e história cultural. Embora concluído o projeto, o corpus possibilita, ainda, inúmeros aprofundamentos e análises, tendo em vista a presença de muitas poesias inéditas de murilo mendes que acompanham as cartas. Esse será um tema de futuros trabalhos.

A última etapa da pesquisa, cujos resultados trazemos aqui, tratou de verificar, a partir de leituras de subsídio teórico, o gênero epistolar e a questão da memória, examinando suas possíveis contribuições para a literatura brasileira. Nesse sentido, compreendemos as epístolas como parte da memória cultural das nações e não apenas como documentos históricos; para nós, o epistolário encontra-se no espaço entre a realidade e a ficção, uma vez que as cartas são escritas com intencionalidade por um eu que expressa sua subjetividade. $O$ ato de escrever implica, portanto, registrar-se na história.

\section{LITERATURA EPISTOLAR, MEMÓRIA E HISTÓRIA}

Mais antigo que as famosas epístolas de Cícero, Horácio e Sêneca, o gênero epistolar, também presente na Bíblia, surge primeiramente com função jornalística, sendo as epístolas um meio imprescindivel de comunicação de dados e informações relevantes à sobrevivência das primeiras sociedades letradas.

Ao longo da história, as cartas foram obtendo um caráter mais didático, no qual o remetente pretende passar alguns preceitos ao endereçado, e.g., Quintus Horatius Flaccus com espécie de cartas poéticas que retomam os assuntos e a entoação das Satirae, porém mais pacatamente: assim, constituem verdadeiras palestras, divagações, confissões sobre a moral - as vinte Epistulae do primeiro livro - ou sobre a literatura - as três do segundo livro; mais famosa a terceira, conhecida 
como Ars Poetica ou Epistola ad Pisones, na qual Horácio explica os passos que devem ser seguidos pelos Irmãos Pisões no processo de criação literária do poeta romano.

A carta, como gênero, ocupa uma série de formulações, desde a familiar até a elevada, mostrando-se inovadora e múltipla e ganhando uma especialização estilística que predomina até o século XVIII. O itinerário da poesia epistolar, iniciada em Horácio, passa pelo Renascimento e vai alcançar diferentes autores em diversas literaturas.

Do ponto de vista de Toscano (2018) cabe indagar, quando o assunto é cartas, os aspectos próprios da relação da carta com o leitor. Segundo o autor,

(...) cartas são objetos literários paradoxais, pois ao mesmo tempo em que foram fervorosamente colecionadas, editadas, difundidas, comentadas, exatamente como obras de fato e de direito, foram reduzidas ao estatuto subalterno de dados biográficos ou psicológicos para servir à história de um homem e, eventualmente, de uma obra. De SainteBeuve até Lanson, foi consenso pensar que seu interesse maior, e inestimável, era o de mostrar-nos algo da humanidade inscrita naquelas palavras. [...]

Mas não nos deixemos enganar pela suposta clareza com que certas ideias manifestam-se nesta expressão diretamente orientada a interlocutores privilegiados, em instância costumeiramente privada - a menos que, conforme nos deixaram pistas eloquentes, de Platão a Goethe e Schiller, ou de Mário de Andrade a Manuel Bandeira, tais escrituras tenham sido construídas já com o intuito de oferecer uma pública e notória articulação conceitual de um projeto nem tão velado assim. (TOSCANO, 2018, p. 77)

$\mathrm{Na}$ literatura, entendemos que o gênero epistolar acaba por se dividir em dois subgêneros: A Literatura Epistolar e A Ficção Epistolar. Fazem parte do segundo subgênero textos nos quais os autores se apropriam da carta como recurso para criar personagens e/ou estruturar obras ficcionais, sendo mais comum em contos, novelas e romances, como Lady Susan, de Jane Austen. Já o primeiro subgênero compreende não somente o clássico epistolário, como também textos em que a voz do autor se faz presente relatando o fazer literário, introduzindo ou justificando sua obra. São exemplos de textos considerados Literatura 
Epistolar prólogos de determinadas obras e, como no caso do objeto desta pesquisa, o epistolário de Murilo Mendes no qual ele revela a Guilhermino César seu processo criativo e aspectos relevantes sobre a produção literária no Brasil, durante o século XX.

Rebello e Rodolfo (2015) afirmam que, no que diz respeito às relações interdisciplinares, uma carta pode estabelecer uma relação estreita com a história, seja da vida de seu autor, seja, também, com a história de um país. Nas palavras dos autores,

as cartas são capítulos da vida de um personagem central e, por vezes, de tantos outros periféricos. Como relatos minúsculos da vida, portanto sujeitos a uma espécie de transitoriedade da incoerencia, as cartas apresentam aspectos romanescos pela inviabilidade do contínuo, pelo fragmentário e pelo inesperado da vida (REBELLO; RODOLFO, 2015, p. 83).

O discurso epistolar, portanto, não é simplesmente uma maneira de anunciar de forma absoluta os acontecidos. As cartas são meios que permitem perceber "tanto a vida particular quanto a vida pública de determinadas personagens por um vies talvez menos fantasioso e mais próximo do real" (REBELLO; RODOLFO, 2015, p. 84).

Ainda que não seja a Literatura Epistolar um gênero ficcional, as cartas podem vir a ser permeadas de certa ficcionalidade, uma vez que têm origem no discurso e na memória humana. Elas são, portanto, fruto da realidade externa mais a percepção daquele que escreve e, desse modo, como afirma Bettiol,

ainda que seja considerada do ponto de vista histórico, a carta, como documento, não está incólume no que se refere à invenção ou à ficção. (...) Os documentos históricos e literários não divergem no seu estatuto de criação, isto é, não no seu estatuto de constructo, de artifício regulado por um conjunto convencional de leis ou práticas (BETTIOL, 2008, p. 22).

Sobre a carta como documento, é consenso, entre aqueles que a estudam, a ideia de que textos de cunho epistolar visam primeiramente à comunicação. Nada mais óbvio, se for levado em consideração que essa prática, troca de missivas, nada mais é que um diálogo entre dois sujeitos. 
Analiticamente, no entanto, uma carta pode representar um documento de grande valor não só para os dois sujeitos do diálogo, como sobretudo para estudos futuros, uma vez que uma missiva pode transcender a simples notícia pessoal e apoderar-se, de forma muito explícita, de múltiplas searas do conhecimento.

Dessa maneira, podemos apontar que a Literatura Epistolar abarca a história como um de seus elementos imprescindíveis, ainda que a epístola tenha sido escrita a partir da memória daquele que a escreve. Nesse sentido, a carta configura-se como meio notável na história e na memória cultural das gentes por meio das marcas nela armazenadas. A epistolografia é, especialmente no caso da história brasileira que inicia com A Carta de Pero Vaz de Caminha, essencial para a reconstituição da memória e da história de um indivíduo e seu contexto sociocultural. Como afirma Paiva, a escrita de cartas,

antes mesmo de ser uma reconhecida forma de se comunicar produzindo interação social, é um ato intrinsecamente ligado à memória e, como tal, também ligado ao arquivamento do eu. Institui-se como suporte dessa mesma memória capaz de transmitir para a posteridade eventos e sentimentos de uma época. Mas para que se escrevem cartas? Para conhecer e ser conhecido; para se informar, expressar opiniões e sentimentos, narrar acontecimentos; para alívio próprio, para ser lido por um ou por muitos (PAIVA, 2006, p. 28).

O estudo de cartas traz à tona detalhes sobre a vida e a produção de figuras da nossa literatura, além de servirem como testemunho de determinadas épocas e se constituírem como patrimônio histórico e cultural (XAVIER, 2012). Segundo a autora,

ao escrever, exercitamos, sobretudo, o direito à memória e ao passado. Podendo manejar o texto, abrimos a possibilidade de manipulação da memória que se quer manter do eu daquele que escreve. Informações selecionadas permitem que o autor/remetente se inscreva na memória, seja de seu povo, seja de um círculo mais restrito, da maneira como ele muitas vezes se vê. $\mathrm{O}$ processo de escrita epistolográfica funciona, por vezes, como um espelho no qual colocamos, no papel, as 
informações e os sentimentos que ressaltam o modo como nos relacionamos com o mundo e como nos enxergamos dentro dele (XAVIER, 2012, p. 14).

Ou seja, "a memória é um elemento essencial do que se costuma chamar identidade, individual ou coletiva, cuja busca é uma das atividades fundamentais dos indivíduos e das sociedades de hoje, na febre e na angústia"(LE GOFF, 2003, p. 469). E acrescenta ainda o autor que "a memória, na qual cresce a história, que por sua vez a alimenta, procura salvar o passado para servir ao presente e ao futuro" (p. 471).

\section{O EPISTOLÁRIO DE MURILO MENDES}

Filho de um funcionário público, Murilo Mendes iniciou-se na criação literária demarcando seu gosto pelas alegorias e pelo humor. Segundo Gonzaga (2009), o escritor deixa-se transparecer intencionalmente em seus versos e faz uso de imagens desconcertantes e símbolos de abstração acentuada. Murilo denega, assim como Carlos Drummond de Andrade, a forma e o juízo comum da modernidade como meio de "libertação" empregados por outros poetas de sua época. Para Bosi (1994), o resultado estético criado pelo poeta só não incorre em total caos porque ele compõe seus estilhaços imaginados em um elemento arquitetônico ordenado, porém incomensurável, e, desse modo, essa desarticulação da forma convencional é, em sua obra, somente um passo primário para a recuperação de um paraíso que se abre aos olhos do poeta como um universo motivado pelo indulto. Muitos autores, ainda, apontam que a característica do religioso e do misticismo das obras de Murilo seria comparável às obras de Cecília Meireles. Murilo Mendes é poeta da colagem do ser,

poeta cósmico e social que aceita a fruição dos valores primordiais. Tendo mantido firme a sua ânsia libertária (...) jamais cai em formas antiquadas de apologética. Místico, ele perfura a crosta das instituições e dos costumes culturais para morder o cerne da linguagem religiosa, que é sempre ligação do homem com a totalidade. Esse sentido geral de sua obra, a que só escapa o ciclo de poemas humorísticos anteriores a 30. (BOSI, 1997, p. 447) 
Murilo não foi consagrado à sua época muito provavelmente devido ao seu senso de humor ácido. A publicação de Poemas, de 1930, que lhe rendeu o Prêmio Graça Aranha, só ocorreu porque foi financiada por seu pai. Seu gosto pelo irônico, expresso sempre em sua visão de um Brasil amatutado e monótono, bem se revela em sua paródia ao poema de Gonçalves Dias, Canção do Exílio, publicado em 1930:

Minha terra tem macieiras da Califórnia
onde cantam gaturamos de Veneza.
Os poetas da minha terra
são pretos que vivem em torres de ametista,
os sargentos do exército são monistas, cubistas,
os filósofos são polacos vendendo a prestações.

A gente não pode dormir com os oradores e os pernilongos.

Os sururus em família têm por testemunha a Gioconda.

Eu morro sufocado

em terra estrangeira.

Nossas flores são mais bonitas

nossas frutas mais gostosas

mas custam cem mil réis a dúzia.

Ai quem me dera chupar uma carambola de verdade

e ouvir um sabiá com certidão de idade!

(MENDES, 1994, p. 87)

As cartas que Murilo Mendes, aos vinte e sete anos, endereça a Guilhermino César, quando este estava a cargo da página literária do jornal Estado de Minas, contêm poemas. O corpus ao qual nos dedicamos, portanto, não se limita a epístolas com temática interpessoal, mas abrange o empenho de um poeta em ser publicado em jornal de boa circulação. Desse modo, a função da carta (a necessidade de comunicar, de contar e de informar) integra, à natureza poética, finalidades mais subjetivas. As cartas e os poemas de nosso epistolário mediam passado e presente como mosaicos articulados, uma vez que instituem nexo entre espaços, aproximam quem está aqui e agora do que, distante, se perde no tempo.

Diante do exposto sobre a natureza da questão a ser investigada, o objetivo principal da pesquisa procurou estabelecer a relação entre vida cultural e individual, pois a leitura analítica das cartas de Murilo Mendes a Guilhermino César permitiu o conhecimento da figura humana, de suas preocupações essenciais em dado período, da forma como as expressa 
utilizando o recurso epistolar e demonstrando igualmente a história cultural do país em certos momentos.

Diferentemente da obra citada do escrivão português, as epístolas escritas por Murilo Mendes são concisas, sendo algumas curtas como um simples bilhete e outras carregadas em explanações e observações. Tão diferentes são as estruturas das correspondências quanto os seus conteúdos, que abarcam desde relações interpessoais e amorosas a comentários críticos sobre a produção literária da época. No Brasil, como é o caso das conversas entre Murilo Mendes e Guilhermino César, muitos poetas utilizaram a carta como antessala de seu processo de criação literária, fazendo dela ferramenta imprescindível para a articulação, a conservação e a difusão de inconfundíveis ideais que aviavam as novidades estéticas que estavam por se delinear neste período histórico. A primeira carta de nosso corpus data do ano de 1928 e nela podemos observar uma maior cordialidade que intimidade, assim como uma melhor caligrafia e qualidade de papel do que nas próximas ocasiões de comunicação de Murilo a Guilhermino. Veja-se a carta:

\section{Praia de Botafogo _-_-_-_ $400 \quad 26.12 .28$}

Ao Guilhermino Cesar e ao Fco. Peixoto

Chegando de Petrópolis onde fui passar alguns dias encontro na minha mesa o livro de vocês. Lhes agradeço a boa lembrança___li o livro com toda atenção e achei que a gente deve esperar muito de vocês___Sinto não ter autoridade (aparente) pra lhes dizer algumas coisa___talvez mais tarde___em todo o caso. Acho que o problema brasilero, integra-se no universal___essa é a grande tendência que anda agora no ar.

Em retribuição aqui têm vocês alguns dos meus poemas que poucos conhecem___escolhidos das dezenas e dezenas que enchem as gavetas___não que sejam dos melhores___mas porque são os únicos de que tenho cópia___tudo quanto escrevo é terrivelmente impessoal__nunca me fixei até agora___nem quero___não sou um omem___sou dezenas deles. Me mandem outros poemas___me interesso pela evolução de vocês.

Notícias do Henrique? 
Aperto de mão do

\section{Murilo Mendes ${ }^{89}$}

No epistolário de Murilo, como se percebe na carta acima, o poeta expressa claramente comentários sobre integrantes de seu ciclo de amizades e seus comentários críticos sobre a literatura brasileira da época e as movimentações sociais e literárias que ocorriam no país. Nesta primeira carta, endereçada a Francisco Inácio Peixoto e a Guilhermino César, Murilo faz uma reflexão sobre "o problema brasileiro" que seria, lembrando que o poeta se integra à poesia moderna radical brasileira cujos membros mais conhecidos são Carlos Drummond de Andrade e João Cabral de Melo Neto, o encontro de uma "real brasilidade" na poesia brasileira.

O fato de observarmos atentamente a carta física foi essencial para que pudéssemos posicionar de modo espacial o poeta durante seu diálogo epistolar reservado com Guilhermino. Sob o papel, se pôde notar, além da letra de Murilo que varia de acordo com o assunto tratado em cada carta, os emblemas presentes que puderam evidenciar alguns registros sobre a vida do poeta feitos por teóricos da literatura brasileira e, ainda, inaugurar a comparação entre suas localizações e as temáticas próprias de suas poesias.

Ao escrever as cartas para Guilhermino César, Murilo Mendes fazse autor de sua própria história, no entanto não o autor (imagem histórica) que estamos acostumados a atribuir-lhe e sim o autor de sim mesmo. Isso porque o remetente não tem a necessidade de um comprometimento (jornalístico) com a verdade ao narrar acontecimentos. A escrita é permeada pela subjetividade do autor e, como afirma Gomes,

o que passa a importar (...) é exatamente a ótica assumida pelo registro e como seu autor a expressa. Isto é, o documento não trata de "dizer o que houve", mas de dizer

${ }^{89}$ Carta de Murilo Mendes a Guilhermino Cesar; datada Rio de Janeiro, 26.12.28; apresenta a localização geográfica Praia de Botafogo 400 escrita/assinada a tinta preta: Murilo Mendes; 1 folha (papel timbrado do Banco Mercantil do Rio de Janeiro); escrita frente e verso; texto ocupando 18 linhas na parte da frente e 12 linhas do verso; sinal de 2 dobras; não ficam claros quais foram os poemas enviados em retribuição. 
o que o autor diz que viu, sentiu experimentou, retrospectivamente, em relação a um acontecimento (GOMES, 2005, p. 14).

É por meio da narrativa de sua(s) carta(s) que um remetente comunica ao(s) destinatário(s), suas experiências; nesse sentido, informa sobre o passado/presente e "amplia a base da memória coletiva", imortalizando-o, desse modo, por meio da linguagem, e situando-o na história e, também, os sujeitos implicados nessas vivências.

Vejamos trechos de algumas cartas do corpus:

Praia de Botafogo 400

Rio, 19.06.29

Guilhermino Cesar,

Estou terrivelmente em falta com você. Pode crer que não tenho tempo pra nada. É um inferno. Recebi o leite Criôlof. Acho que é uma tentativa digna de todas as palmas, mas me parece que vocês deviam dar uma feição mais pessoal à revista. Sem querer sente-se a Antropofagia ali. Não acho que se deva rejeitar influências (nem se pode)___mas que se deve ajuntar várias experiências pra formar uma cultura ou ensaiar qualquer reforma.

[...]

Disponha sempre do

Murilo Mendes ${ }^{90}$

a/c Dr. Onofre Mendes Junior - Pitangui

Pitangui - 18.12.30

${ }^{90}$ Fragmento de carta de Murilo Mendes a Guilhermino Cesar; datada apenas Rio, 19.06.29; escrita/assinada a tinta preta: Murilo Mendes; 1 folha com a localização geográfica Praia de Botafogo, 400; escrita somente na frente da folha; texto ocupando 19 linhas; Sinal de 2 dobras; 2 furos de arquivamento; apresenta marcas de bolor. 
Guilhermino,

Como vai o Bar do Ponto?

Tenho 2 namoradas__uma é Decroli (no namoro)___outra, não. Que pena não poder casar com as duas. As dimensões atrapalham a gente. Só abstraindo o tempo e o espaço.

Quem fala aqui é o colaborador do "Estado de Minas". Soube que ele botou os "Poemas de Itararé", houve grande sucesso e muita falação aqui na Oeste, só uma pessoa não leu: o autor.

[...]

Não tenho cópia. Eu acho que é de 12 .

Me recorte e mande dentro dum envelope, mandando por lá a eles botem no correio.

[...]

Abraços Carlos, Nava, Carlos Drummond de Andrade.

Adeus.

Cordial abraço

Murilo Mendes $^{91}$

Mandei Mário de Andrade, Cícero Dias e Jorge de Lima, entre outros, ótimo "Natal Revolucionário".

Pitangui - 31.XII.30.

Guilhermino

Confirmo carta 26 ou 27 seguem colaborações 1 Reis acho um pouco comprido todo caso veja possível sair tenho

${ }^{91}$ Fragmento de carta de Murilo Mendes a Guilhermino Cesar; datada apenas Pitangui, 18.02.30; escrita/assinada a tinta azulada: Murilo Mendes; 2 folhas; escrita somente na frente das folhas; texto ocupando 36 linhas. 
outras tantas [...] mas acho já tem muita coisa minha aí. Junto artigo Bandeira você diz não leu peço devolver só tenho este Bandeira me escreveu dizendo não poder se estender feitio jornal espaço.

[...]

Cordial abraço

Murilo M. ${ }^{92}$

Se os relatos contidos nas epistolas podem ser decifrados como engenharia contra o esquecimento, do mesmo modo é também adequado refletirmos sobre o fato de estes relatos serem levantados pelo remetente como forma de dar vida às suas memórias individuais e também coletivas. Para Jaques Le Goff (2003, p. 434), a memória seria justamente "o antídoto do Esquecimento", lembrando ainda da mitologia grega quando, no inferno órfico, "o morto deve evitar a fonte do esquecimento, não deve beber no Letes, mas, ao contrário, nutrir-se da fonte da Memória, que é uma fonte de imortalidade" (LE GOFF, 2003, p. 434).

Com relação à memória e ao processo de construção da identidade coletiva, Nickel (2012, p. 14) explica que "fora do discurso, não há possibilidade de preservação, nem de transmissão da memória”, portanto, narrar é a forma que os seres humanos têm de documentar e conferir às suas experiências o caráter de reais. Nickel acrescenta, ainda, que

o processo de construção da identidade coletiva pode ser pensado de forma análoga, na medida em que está só existirá a partir da sua integração na linguagem. Em outras palavras, a construção da identidade de um grupo depende da inscrição das experiências dos indivíduos que o constitui no discurso, numa narrativa histórica - ou ainda, em narrativas históricas. A entrada no discurso, na ordem simbólica, é imprescindível para a construção da memória e da história (NICKEL, 2012, p. 14).

A partir das articulações supracitadas, quando analisamos o corpus desta pesquisa, passamos a compreender as articulações entre o autor

92 Fragmento de carta de Murilo Mendes a Guilhermino Cesar; datada apenas Pitangui - 31.XII.30; escrita/assinada a tinta preta: Murilo M.; 1 folha escrita apenas na frente; texto ocupando 19 linhas. 
Murilo, comumente conhecido, e o self-autor Murilo de seu epistolário. Nesse sentido, fica explícita a sua importância histórica para (re)constituir, de forma a contextualizar, o panorama histórico-social, literário e cultural brasileiro do começo do século XX.

Quando se analisam as cartas de Murilo Mendes endereçadas a Guilhermino Cesar vem-nos à mente o que Compagnon (2006) afirma, a saber, que intenção do autor não é premeditada nem totalmente consciente. Diz ele ser a arte uma atividade intencional, mas que, no entanto, há inúmeras atividades intencionais não premeditadas nem intencionais. Em suas palavras, escrever

não é como jogar xadrez, atividade em que todos os movimentos são calculados; é mais como jogar tênis, um esporte no qual o detalhe dos movimentos é imprevisivel, mas no qual a intenção principal não é menos firme [...]. A intenção do autor não implica uma consciência de todos os detalhes que a escritura realiza, nem constitui um acontecimento separado que precederia ou acompanharia a performance, conforme a dualidade falaciosa dos pensamento e da linguagem (COMPAGNON, 2006, p. 91).

Assim, pode-se afirmar, após as inúmeras análises do corpus, que Murilo, embora com intenção de se mostrar e de levar a sua obra a Guilhermino, deixa muito mais a ver em seu texto, muito do que ele conscientemente e intencionalmente não estava ciente de estar evidenciando.

\section{Palavras finais}

Do ponto de vista de Rodolfo (2014) expor cartas de um autor pode configurar invasão de privacidade, revelando situações que não seriam divulgadas publicamente. Todavia, "em grande medida, as cartas têm o poder de tornar viva a obra do autor como um todo" (RODOLFO, 2014, p. 87). Por sua vez, Tin (2005) afirma que,

o conteúdo documental da carta de um escritor estaria submetido a duas mediações: uma, do próprio gênero epistolar, que seria a orientação do discurso conforme o destinatário a quem se dirige, e segundo o assunto, a 
situação em que o autor se encontra etc.; outra, decorrente de sua condição de escritor, que recriaria sua experiência pessoal conforme o seu crivo altamente seletivo a que estaria sujeito o material linguístico da carta (TIN, 2005, p. 9).

A pergunta a ser feita, então, segundo o autor, é se carta constitui literatura ou se configura apenas como "um material auxiliar para o conhecimento de seu autor, de problemas relacionados com a sua obra, de suas concepções e de seu ambiente social"? A resposta à sua indagação é positiva, cartas constituem literatura (TIN, 2005, p. 10).

Em síntese, o estudo da correspondência de Murilo Mendes para Guilhermino Cesar é de grande importância pelo muito que acrescenta à biografia do poeta; é também fonte rentável de pesquisa, no que diz respeito à vida de figuras relevantes da literatura e da cultura brasileira da época, além de seu grande valor literário em virtude também dos poemas nelas inseridos (REBELLO; RODOLFO, 2017, p. 216).

As cartas do conjunto elucidam questões que permeavam a criação literária, a sociedade e a cultura brasileiras do final dos anos vinte do século passado e, de seu ponto de vista, as cartas de Murilo confirmam o que refletiu Tania Carvalhal sobre o tema, ou seja, que elas "não nos levam apenas a seu destinatário, ou ao periódico onde os poemas se publicam, mas à poesia brasileira, ao momento vivido e ao conjunto de sua obra” (CARVALHAL, 2003, p. 61).

\section{REFERÊNCIAS}

BETTIOL, M. R. A escritura do intervalo: a poética epistolar de Antônio Vieira. São Leopoldo: UNISINOS, 2008.

BOSI, A. História concisa da literatura brasileira. São Paulo: Cultrix, 1994.

CARVALHAL, T. F. Cartas e Poemas de Murilo Mendes: breve notícia. In: Scripta, Belo Horizonte, v. 6, n. 12, 1º sem. 2003, p. 55-61.

COMPAGNON, A. O demônio da teoria: literatura e senso comum. Trad.

Cleonice Paes Barreto Mourao e Consuelo Fortes Santiago, Belo Horizonte: Editora da UFMG, 2006.

GOMES, A. de C. (org.). Em familia: a correspondência de Oliveira Lima e Gilberto Freyre. Campinas, SP: Mercado das Letras, 2005. 
248 | Lis Yana de Lima Martinez e Lúcia Sá Rebello

GONZAGA, S. Curso de literatura brasileira. 3. ed. Porto Alegre: Leitura XXI, 2009.

LE GOFF, J. História e memória. Trad. Bernardo Leitão et al. 5. ed. Campinas, SP: Editora Unicamp, 2003.

MENDES, M. Poesia completa e prosa. Rio de Janeiro: Nova Aguilar, 1994.

NICKEL, V. Trauma, memória e história em A Mercy, de Tony Morrison [manuscrito].

Disponível

em:

https://www.lume.ufrgs.br/bitstream/handle/10183/-

61717/000865266.pdf?sequence=. Acesso em: 19 abr. 2019.

PAIVA, K. B. Histórias de vida e amizade: as cartas de Mário, Drummond e Cecília para Henriqueta Lisboa. 2006. Dissertação (mestrado em Letras) Universidade Federal de Minas Gerais. Belo Horizonte.

REBELLO, L. S.; RODOLFO, L. Meu caro Guilhermino ...: análise de duas cartas de Murilo Mendes para Guilhermino Cesar. In: REBELlO, L. S.; FLORES, V. do N. Caminhos das letras: uma experiência de integração. Porto Alegre: Editora da UFRGS, 2015. p. 78-100.

REBELLO, L. S.; RODOLFO, L. Registro de errâncias: Murilo Mendes escreve a Guilhermino Cesar. In: BITTENCOURT, R. L. et alii (Org.). Espaço/espaços: estudos de literatura comparada. Porto Alegre: Editora da UFRGS, 2017. p. 199-2017.

RODOLFO, L. A vida às margens da arte: a correspondencia e a poesia inéditas de Murilo Mendes a Guilhermino Cesar. Tese (doutorado) Universidade Federal do Rio Grande do Sul. Instituto de Letras. Programa de Pós-Graduação em Letras, Porto Alegre, BR-RS, 2014. Disponível em:

https://lume.ufrgs.br/bitstream/handle/10183/114424/000951498.pdf? sequence $=1$ \& isAllowed $=y$. Acesso em: 22 abr. 2019.

TIN, E. Cartas e literatura: reflexões sobre pesquisa do gênero epistolar. Disponível em: https://www.unicamp.br/iel/monteirolobato/outros/Emerson02.p df. Acesso em: 23 abr. 2019.

TOSCANO, A. R. Remetentes e destinatários: se é que existem! Disponível em: http://periodicos.ufes.br/farol/issue/view/n.\%2019/showToc. Acesso em: 20 abr. 2019.

XAVIER, A. F. Humor no lirismo: a escrita epistolar de Murilo Mendes. Trabalho de conclusão (Graduação) - Universidade Federal do Rio Grande do Sul. Instituto de Letras, Porto Alegre, BR-RS, 2012. 
Murilo Mendes: memória e vida cultural | 249

Disponível em: https://lume.ufrgs.br/handle/10183/56157. Acesso em: 23 abr. 2019.

Recebido em: 30/03/2019

Aceito em: 10/04/2019 